\title{
Study on Incidence of Needle Stick Injury and Factors Associated with this Problem among Medical Students
}

\author{
Mohamad Yaakob NorsAYANI and Ismail Noor Hassim \\ Department of Occupational Safety and Health (DOSH), Malaysia
}

\begin{abstract}
Study on Incidence of Needle Stick Injury and Factors Associated with This Problem among Medical Students: Mohamad Yaakob Norsayani, et al. Department of Occupational Safety and Health (DOSH), Malaysia-Medical students face the threat of needle stick injury with the consequent risk of acquiring blood-borne infection by pathogens such as HIV, Hepatitis B and Hepatitis C while performing their clinical activities in the hospitals. A cross-sectional study was conducted among 417 final year medical students from Universiti Kebangsaan Malaysia (UKM), University Malaya (UM) and Universiti Putra Malaysia (UPM). The aims of the study were to determine the incidence of cases and episodes of needle stick injury among them in the past year. This study was also done to find out the factors that might be associated with the occurrence of this problem. The factors were sociodemographic factors, duration of exposure, level of knowledge of blood-borne diseases and Universal Precaution, perception of risk of blood-borne diseases and level of practice of Universal Precaution. The incidence of needle stick injury among medical students was $14.1 \%$ (59 cases). The total number of episodes of needle stick injury was 87 and the incidence of episodes among respondents was high i.e. $20.9 \%$. The highest incidence of episodes of needle stick injury occurred in Obstetric \& Gynaecology postings, followed by Medicine and Surgery. For clinical procedures, venepuncture had the highest incidence followed by setting up drips and giving parenteral injections. The results showed the students who had needle stick injury (cases) had lower scores in the practice of Universal Precautions than non-cases $(p<0.05)$. There was a significant association between the level of practice of Universal Precautions and the number of episodes of needle stick injury, i.e. the higher the score for the practice of Universal Precautions, the lower the number of episodes $\left(\beta=-2.03 \times 10^{-2}, \mathrm{p}<0.05\right)$. This study showed that medical students are at risk of needle stick
\end{abstract}

Received Sep 5, 2002; Accepted April 7, 2003

Correspondence to: M. Y. Norsayani, Department of Occupational Safety and Health (DOSH), Tingkat 3, Bangunan Persekutuan, Jalan Gambut, 25000 Kuantan, Pahang, Malaysia injury and blood-borne infections during their clinical activities while performing procedures on patients especially for those who were poor at practising Universal Precautions. Therefore some preventive measures should be taken by the management of the universities and medical students to avoid the occurrence of these problems.

(J Occup Health 2003; 45: 172-178)

Key words: Needle stick injury, Incidence, Medical Students

Medical students who are exposed to needles in their clinical activities are at increased risk of acquiring needle stick injury, which may lead to serious or fatal infections with blood-borne pathogen infections such as hepatitis B virus (HBV), hepatitis C virus (HCV), or human immunodeficiency virus (HIV) ${ }^{1,2)}$. The activities associated with the majority of needle stick injuries are administering injections, withdrawing blood, recapping needles, disposing of needles, handling trash and dirty linen ("downstream injuries") and while attempting to transfer blood or other body fluids from a syringe to a specimen container (such as a vacuum tube) and misses the target ${ }^{3,4)}$.

The National Institute for Occupational Safety and Health (NIOSH), USA defines needle stick injuries as injuries are caused by needles such as hypodermic needles, blood collection needles, intravenous (IV) stylets, and needles used to connect parts of IV delivery systems ${ }^{3)}$. The Ministry of Health of Malaysia defines needle stick injuries as injuries caused by suture or hollow-bore needles ${ }^{7)}$. Hollow-bore needles (the type of needles used for giving injections or withdrawing blood) also are implicated as devices most often associated with the transmission of blood-borne pathogen infections, because the blood remaining inside the bore of the needle after use contains a larger volume of viruses than the relatively small amount of blood remaining on the outside of a solid core needle such as a suture needle ${ }^{4)}$. Therefore, hollowbore needles pose a higher risk of infection in health care workers including medical students. 
Although the risk of human immunodeficiency virus (HIV) infection through occupational exposures to blood has received considerable attention, relatively few studies have addressed blood exposure accidents among medical students $^{6-8)}$. In Malaysia, the problem of exposure to contaminated blood among 4,534 medical students in six local universities at a given time has received very little attention. Until today, there were only two local studies about the risk of needle stick injuries among medical students done in 1995 and 1999 at Hospital USM, Kubang Kerian, Kelantan by Naing et al. who studied the prevalence of needle stick injuries in the entire years of 1995 and 1999, 10). Both studies had shown a high prevalence of needle stick injuries. In the former study, $38.3 \%$ of respondents had experienced this type of injury and in the latter study $24.7 \%$ had. The study done in 1999 showed that the highest number of needle stick injuries occurred during Obstetric \& Gynaecological work, while performing venepuncture and when recapping needles.

Previous studies on needle stick injuries were mainly focused on the prevalence of the injuries and the injury trends among medical students. But little is known about the factors that may be associated with the occurrence of this problem such as individual factors in the medical students, patients' factors, the device factor and the management factor. Examples of the individual factors are lack of knowledge of blood-borne diseases and Universal Precautions, lack of experience in performing the procedures, poor practice by not complying with Universal Precautions and poor risk perception concerning the consequences of needle stick injury. It is hoped that by identifying the factors associated with this problem, some modification can be made to protect students against this unnecessary risk. So far, there had been no study on the prevalence of needle stick injury caused by hollow-bore needles, even though it poses a high risk of infection by blood-borne pathogens.

The objectives of this study are to determine the prevalence of needle stick injuries among medical students in terms of the number of cases and episodes of the injuries for the past one year. This study also aims to determine the level of knowledge, risk perception and practice for cases and non-cases of needle stick injury and the factors that may be associated with the occurrence of this problem. The hypotheses are that the mean score for knowledge in cases of needle stick injury is lower than in non-cases, and also the mean score of the practice of Universal Precautions is lower. An increase in the score for knowledge and practice will reduce the episodes of needle stick injuries among medical students.

\section{Materials and Methods}

This was a cross-sectional study which was divided into an incidence study on needle stick injury and a study on the level of knowledge, risk perception and practice of Universal Precautions. This study was done among 428 final year medical students by universal sampling in three local universities, the University Kebangsaan of Malaysia (UKM), Malaya University (MU) and University Putra of Malaysia (UPM) in August to September 2001. The students were asked about their experience of needle stick injuries from August 2000 to August 2001 when the students were in fourth year and early final year. At the time of the study, most of the students had completed all their clinical postings and had done most of the basic clinical procedures required by the medical schools.

Most of the students had undergone seven main clinical postings i.e. Obstetric \& Gynaecology, Medicine, Surgery, Accidents \& Emergency, Orthopaedic, Paediatric and Psychiatry except for some students from UPM and UKM who had not yet gone through some of the postings during the study period. The medical students are required to perform procedures involving needles, for example venepuncture, setting up intravenous drips, giving parenteral injection and a few other activities that put them at risk of needle stick injuries.

In this study, needle stick injury was defined as percutaneous injury caused by hollow-bore needles (the type of needle used for giving injections or drawing blood), which has a bore where blood can remain inside after use. Suturing needles were not included. Cases of needle stick injuries were the number of respondents who have had at least one experience of needle stick injury. And the episodes of needle stick injuries were the number of injuries that were experienced by the respondents. The incidence of cases was the number of cases per number of respondents and the incidence of episodes was the number of episodes per number of respondents.

The students were asked to complete the questionnaires, which were returned right after the session and some after a week. In the questionnaires, they were asked about their experience in handling needles and the incidence of needle stick injury caused by hollow bore needles in the past one year. The respondents were also asked about their knowledge of blood-borne diseases and Universal Precautions. For blood-borne diseases, the questions were about HIV/Aids, Hepatitis B and Hepatitis $\mathrm{C}$ and Universal Precautions; they were also asked about types of secretions and the guidelines. The total score for knowledge of blood-borne diseases was 40 (40 true/ false questions) and for Universal Precaution was 12 (12 true/false questions). The mean scores for both types of knowledge were taken for this study. For practice of Universal Precautions, there were 10 questions about the practice of Universal Precautions that should be and should not be done while doing procedures in hospitals, according to the guidelines on Universal Precautions. The total score was 40 and the mean score was taken as the 
result for the study.

These data were analysed with SPSS 10.0 software. Chi-square analysis and Student's t-test were used to find the differences between cases and non-cases for the factors associated with the occurrences of needle stick injury. Multiple linear regression was applied to determine the relationship between the associated factors and needle stick injury.

\section{Results}

A total of 417 of the 428 questionnaires were returned for a response rate of $97.4 \%$. The majority of the students were Malay $(64.3 \%)$, female $(58.5 \%)$ and their mean age was $23.91 \pm 1.05 \mathrm{yr}$ old. Three hundred and eighty-eight students $(93.0 \%)$ had received the hepatitis B vaccine but about 31 students $(10.1 \%)$ had not completed the course of three injections and this was because they were already positive to HBV antibodies, busy on the day of the vaccination or could not bear the cost of vaccination (Table 1).

All the students handled hollow-bore needles in their clinical postings. The percentages of students who agreed that in the postings the needles they handled most were in Obstetrics \& Gynaecology (96.4\%), followed by Medicine (60.7\%), Accidents and Emergency (60.2\%) and Surgery $(51.1 \%)$. Meanwhile the most common procedures involving handling needles were venepuncture $(99.5 \%)$, setting up drips $(95.0 \%)$ and giving parenteral injections $(71.0 \%)$. The median number of minutes spent per week performing procedures involving needles in patients for one student was 220 min per week (ranging from 0 to 1,000 min per week).

Fifty-nine students admitted experiencing at least one needle stick injury, which was an incidence of $14.1 \%$. This showed that needle stick was the commonest type of exposure to blood and body fluids among medical students compared to other forms of exposures such as injury caused by other sharp objects (9.3\%), mucocutaneous exposures $(7.0 \%)$ and contact through non-intact skin $(6.0 \%)$ (Table 2). The case incidence of needle stick injury in UKM was the highest, i.e $16.3 \%$ followed by UPM, $15.4 \%$ and UM, $11.5 \%$, but these differences were not significant statistically (Table 3). There were a total of 87 episodes ranging from 1 to 5 injuries per case. The incidence of these episodes among all medical students was high, i.e. $20.9 \%$ and UPM showed the highest incidence with $29.2 \%$. (Table 4). This study also revealed that the incidence of episodes of needle stick injures according to clinical postings was high in Obstetrics \& Gynaecology (13.2\%) followed by

Table 1. Sociodemographic characteristics and status of hepatitis B of the study population

\begin{tabular}{lcccc}
\hline & UKM & UM & UPM & Total \\
\cline { 2 - 5 } & $\mathrm{n}(\%)$ & $\mathrm{n}(\%)$ & $\mathrm{n}(\%)$ & $\mathrm{n}(\%)$ \\
\hline Faculty of Medicine & $178(42.7)$ & $174(41.7)$ & $65(15.6)$ & $417(100.0)$ \\
Ethnic & & & & \\
$\quad$ Malay & $141(79.2)$ & $98(56.3)$ & $29(44.6)$ & $268(64.3)$ \\
Chinese & $27(15.2)$ & $52(29.9)$ & $24(36.9)$ & $103(24.7)$ \\
$\quad$ Indian & $3(1.7)$ & $16(9.2)$ & $11(13.9)$ & $30(7.2)$ \\
Others & $7(3.9)$ & $8(4.6)$ & $1(1.5)$ & $16(3.8)$ \\
Sex & $75(42.1)$ & $74(42.5)$ & $24(36.9)$ & $173(41.5)$ \\
$\quad$ Male & $103(57.9)$ & $100(57.5)$ & $41(63.1)$ & $244(58.5)$ \\
Female & $23.72 \pm 0.84$ & $24.01 \pm 1.21$ & $24.12 \pm 1.05$ & $23.91 \pm 1.05$ \\
Age (Mean years old) & & & & \\
Hepatitis B vaccination & $166(93.3)$ & $159(91.4)$ & $63(96.9)$ & $388(93.0)$ \\
$\quad$ Yes & $12(6.7)$ & $15(8.6)$ & $2(3.1)$ & $29(7.0)$ \\
$\quad$ No & $143(86.1)$ & $147(92.5)$ & $59(93.7)$ & $349(89.9)$ \\
Immunization status & $23(13.9)$ & $12(7.5)$ & $4(6.3)$ & $39(10.1)$ \\
$\quad$ Complete (3 doses) & & & & \\
$\quad$ Not complete & & & & \\
\hline
\end{tabular}

Table 2. Incidence of exposure according to exposure to blood and body fluids for the past one year

\begin{tabular}{llrrr}
\hline & \multicolumn{4}{c}{$\mathrm{n}(\%)$} \\
\cline { 2 - 5 } & UKM & UM & UPM & Total \\
\hline Needle Stick Injury & $29(16.3)$ & $20(11.5)$ & $10(15.4)$ & $59(14.1)$ \\
Injury Caused By Other Sharp Objects & $18(10.1)$ & $15(8.6)$ & $6(9.2)$ & $39(9.3)$ \\
Mucocutaneous Exposure & $18(10.1)$ & $6(3.4)$ & $5(7.7)$ & $29(7.0)$ \\
Contact Through Non-Intact Skin & $15(8.43)$ & $6(3.4)$ & $4(6.2)$ & $25(6.0)$ \\
\hline
\end{tabular}


Table 3. Incidence of cases of needle stick injury for the past one year according to university, sex and ethnic group

\begin{tabular}{lcccc}
\hline & $\mathrm{n}$ & $\%$ & $\chi^{2}$-value & $\mathrm{p}$-value \\
\hline University & & & & \\
$\quad$ UKM $(\mathrm{n}=178)$ & 29 & 16.3 & 1.764 & 0.414 \\
$\quad$ UM $(\mathrm{n}=174)$ & 20 & 11.5 & & \\
$\quad$ UPM $(\mathrm{n}=65)$ & 10 & 15.4 & & \\
$\quad$ Total $(\mathrm{n}=417)$ & 59 & 14.1 & & \\
Sex & & & & \\
$\quad$ Male $(\mathrm{n}=173)$ & 24 & 13.9 & 0.019 & 0.892 \\
$\quad$ Female (n=244) & 35 & 14.3 & & \\
Ethnic Group & & & & \\
$\quad$ Malay (n=268) & 37 & 13.8 & 0.788 & 0.892 \\
$\quad$ Non Malay (n=149) & 22 & 14.8 & & \\
\hline
\end{tabular}

$\chi^{2}$ test, $*: \mathrm{p}<0.05$
Table 4. Incidence of episodes of needle stick injury for the past one year according to university, sex and ethnic group

\begin{tabular}{lcc}
\hline & $\mathrm{n}$ (no. of episodes) & Prevalence (\%) \\
\hline University & & \\
$\quad$ UKM (n=178) & 47 & 26.4 \\
UM $(\mathrm{n}=174)$ & 21 & 12.1 \\
UPM (n=65) & 19 & 29.2 \\
$\quad$ Total & 87 & 20.9 \\
Sex & & \\
$\quad$ Male $(\mathrm{n}=173)$ & 46 & 25.1 \\
$\quad$ Female $(\mathrm{n}=244)$ & 70 & 28.7 \\
Ethnic & & \\
$\quad$ Malay $(\mathrm{n}=268)$ & 77 & 28.7 \\
$\quad$ Non Malay $(\mathrm{n}=149)$ & 39 & 26.2 \\
\hline
\end{tabular}

Table 5. Incidencre of episodes of needle stick injury for the past one year according to university and clinical postings

\begin{tabular}{lcccc}
\hline \multirow{2}{*}{ Postings } & \multicolumn{4}{c}{ No. of episodes of needle stick injury $(\%)$} \\
\cline { 2 - 5 } Obstetrics \& Gynaecology & UKM & UM & UPM & Total \\
\cline { 2 - 5 } Surgery & $28(15.7)$ & $15(8.6)$ & $12(18.5)$ & $55(13.2)$ \\
& $(\mathrm{n}=178)$ & $(\mathrm{n}=174)$ & $(\mathrm{n}=65)$ & $(\mathrm{n}=417)$ \\
Medicine & $5(2.8)$ & $1(0.6)$ & $1(2.9)$ & $7(1.6)$ \\
& $(\mathrm{n}=178)$ & $(\mathrm{n}=174)$ & $(\mathrm{n}=34)$ & $(\mathrm{n}=386)$ \\
Paediatric & $9(5.1)$ & $3(1.7)$ & $6(19.4)$ & $18(4.7)$ \\
& $(\mathrm{n}=178)$ & $(\mathrm{n}=174)$ & $(\mathrm{n}=31)$ & $(\mathrm{n}=383)$ \\
Accident \& Emergency & $1(2.2)$ & 0 & 0 & $1(0.4)$ \\
& $(\mathrm{n}=46)$ & $(\mathrm{n}=174)$ & $(\mathrm{n}=65)$ & $(\mathrm{n}=285)$ \\
Orthopaedic & $3(1.7)$ & $2(1.2)$ & 0 & $5(1.2)$ \\
& $(\mathrm{n}=178)$ & $(\mathrm{n}=172)$ & $(\mathrm{n}=65)$ & $(\mathrm{n}=415)$ \\
& $1(0.6)$ & 0 & 0 & $1(0.3)$ \\
& $(\mathrm{n}=178)$ & $(\mathrm{n}=174)$ & $(\mathrm{n}=35)$ & $(\mathrm{n}=387)$ \\
\hline
\end{tabular}

$\mathrm{n}=$ number of students who had undergone postings

Medicine (4.7\%) and Surgery (1.6\%) (Table 5).

There were a total of 39 episodes of the needle stick injuries during venepuncture and the incidence of episodes for this procedure was $9.23 \%$, followed by $4.8 \%$ for setting up drips and $2.4 \%$ for giving parenteral injections. The injuries which occurred during venepuncture mainly happened while removing the needle cap and recapping the needle after use. Out of all the cases of needle stick injuries, 51 students $(86.4 \%)$ wore gloves when performing procedures on patients. In only 21 cases $(35.6 \%)$ was needle stick injury reported. The majority of them reported the case to the nurses $(76.2 \%)$, medical officers $(47.6 \%)$ and lecturers $(23.8 \%)$. The major reasons given for not reporting the accidents were the feeling that the exposure was not dangerous because the patient was not a blood-borne pathogen carrier, they were not aware that the accident should be reported and did not know where to report the case.

Most of the students (99.3\%) have acquired knowledge of blood-borne diseases mainly through formal lectures (98.3\%), books (90.8\%) and through lecturers informally $(81.6 \%)$. The percentage of students had who acquired knowledge of Universal Precautions was slightly low (70.3\%), through formal lectures $(77.5 \%)$, books $(50.5 \%)$ and through lecturers informally $(67.2 \%)$. The mean score for knowledge of blood-borne diseases was 34.52 \pm 3.23 with a score range of 8 to 40 . For the knowledge of Universal Precautions, the mean score was $7.94 \pm 1.83$ with a score range of 1 to 12 . The range of scores for the perception of risk of blood-borne pathogen infection was 0 to 9 and the overall mean score was $7.30 \pm 2.15$. For the mean score of practice of Universal Precautions, the overall mean score was $32.95 \pm 3.75$ with a range of 18 to 40 . Some of the wrong practices occurred when 
Table 6. Factors possibly associated with the occurrence of needle stick injury among medical students

\begin{tabular}{|c|c|c|c|c|}
\hline & Cases & Non cases & Tests & $\mathrm{p}$ \\
\hline \multicolumn{5}{|l|}{ University } \\
\hline UKM & 29 & 149 & \multirow[t]{3}{*}{$\chi^{2}=1.764$} & \multirow[t]{3}{*}{0.414} \\
\hline UM & 20 & 154 & & \\
\hline UPM & 10 & 55 & & \\
\hline \multicolumn{5}{|l|}{ Sex } \\
\hline Male & 24 & 149 & \multirow{2}{*}{$\chi^{2}=0.019$} & \multirow[t]{2}{*}{0.892} \\
\hline Female & 35 & 209 & & \\
\hline \multicolumn{5}{|l|}{ Ethnic } \\
\hline Malay & 37 & 231 & \multirow[t]{2}{*}{$\chi^{2}=0.073$} & \multirow[t]{2}{*}{0.788} \\
\hline Non Malay & 22 & 127 & & \\
\hline Median duration of exposure (minute/week) & 215.00 & 240.00 & $\mathrm{z}=0.227$ & 0.820 \\
\hline Mean score of knowledge on blood-borne diseases & $34.34 \pm 3.05$ & $34.55 \pm 3.26$ & $\mathrm{t}=-0.475$ & 0.635 \\
\hline Mean score of knowledge of universal Precautions & $7.69 \pm 1.99$ & $8.00 \pm 1.75$ & $\mathrm{t}=-1.106$ & 0.269 \\
\hline Mean score of risk perception & $7.42 \pm 2.00$ & $7.28 \pm 2.18$ & $\mathrm{t}=0.469$ & 0.639 \\
\hline Mean score of practice of Universal Precautions & $32.14 \pm 3.09$ & $33.08 \pm 3.84$ & $\mathrm{t}=-2.106$ & $0.038 *$ \\
\hline
\end{tabular}

Chi-square test, Mann-Whitney, t-independent test $*: \mathrm{p}<0.05$

Table 7. The relationship between episodes of needle stick injury with possible associated factors

\begin{tabular}{lccc}
\hline \multicolumn{1}{c}{ Factors } & $\beta$-value & Standard Error & p-value \\
\hline Duration of exposure (minute/week) & $3.79 \times 10^{-5}$ & 0.000 & 0.449 \\
Mean score of knowledge of blood-borne diseases & $-1.76 \times 10^{-2}$ & 0.016 & 0.085 \\
Mean score of knowledge of Universal Precautions & $-3.24 \times 10^{-2}$ & 0.024 & 0.067 \\
Mean score of risk perception & $1.24 \times 10^{-2}$ & 0.019 & 0.291 \\
Mean score of practice of Universal Precautions & $-2.03 \times 10^{-2}$ & 0.012 & $0.022^{*}$ \\
Constant & 1.707 & 0.647 & $<0.001^{*}$ \\
\hline & & Linear Regression *: $<<0.05$
\end{tabular}

recapping needles after use, bending used needles, removing a needle from a syringe to transfer blood to the specimen tube and in disposing of needles. Some did not use the proper container for disposal of needles.

The study showed there were no significant differences between cases and non-cases in sosiodemographic factors or the time spent performing procedures on patients in needle stick injury $(p>0.05)$. The mean scores for knowledge of blood-borne diseases and Universal Precautions seen to be lower for cases than for non-cases but these differences were not significant $(p>0.05)$. The difference in the mean score for risk perception also was not statistically significant. The only factor that was identified as an associated factor for the occurrence of needle stick injury was the practice of Universal Precautions, in which cases scored significantly lower than non-cases $(\mathrm{p}<0.05)$ (Table 6).

To determine the relationship between episodes of needle stick injuries with the associated factors, multiple linear regression was performed and the result showed that the mean score for the practice of Universal Precautions was inversely related to the occurrence of needle stick injuries $\left(\beta=-2.03 \times 10^{-2}, \mathrm{p}<0.05\right)$ (Table 7), which meant that an increase in the level of practice of Universal Precautions will reduce the incidence of needle stick injuries among medical students. This study has shown that there was no relationship between cases of needle stick injury and the duration of exposure, knowledge of blood-borne diseases and Universal Precautions or risk perception of the medical students.

\section{Discussion}

This study showed that all the final year students involved in this study were exposed to the risk of exposure to blood-borne diseases such as HIV and AIDS, Hepatitis $\mathrm{B}$ and Hepatitis $\mathrm{C}$ through needle stick injury since all of them handled hollow-bore needles to perform procedures on patients in their routine clinical activities. Moreover, some of them have not yet received Hepatitis B immunization and for those who had incomplete doses of the vaccine might have a low titre of antibodies to $\mathrm{HBV}$ and they were not fully protected from infection by this virus. The incidence of cases of needle stick injuries in this study was considerably high $(14.1 \%)$ but was lower than in two previous local studies. A study done by Naing et al. revealed that the prevalence of needle stick injury 
was $38.3 \%$ in 1995 and $24.7 \%$ in $1999^{9,10)}$. This is perhaps because the two studies included hollow-bore needles as well as suture needles as the causes of needle stick injuries, whereas this study only emphasised hollow-bore needles since the risk of infection via hollow-bore needles is higher.

The incidence of episodes of needle stick injury among the final year medical students was high, i.e. $20.9 \%$. It was not possible to compare the results on case and episode incidence with other studies since there was no study done on hollow-bore needle alone. The incidence of episodes was high in Obstetrics \& Gynaecology and this might be because many procedures in this field require needle handling as in venepunctures, setting up drips, parenteral injections to mothers and babies, and giving local analgesia for episiotomies, etc. This study revealed that venepuncture was the most common procedure done by medical students and this might be the reason why many cases of alleged needle stick injury occurred while performing this procedure. Naing et al. (1999) showed similar findings where Obstetrics \& Gynaecology and venepuncture were the posting and procedure with the highest prevalence ${ }^{10)}$.

The incidence of episodes of needle stick injuries was high during taking off the cap and recapping the needle after used. The problem which arose during taking off the cap might be due to the mechanical design of the needle which caused difficulty in opening the cap and the students might have accidentally injured themselves. Even though the student was not at risk of infection with the blood-borne pathogens since the needle was sterilized, if the student was a carrier of blood-borne pathogens, the viruses may be transmitted to the patients. Similarly, if the patients were the carriers, an open skin barrier due to the needle stick injury will pose a high risk of infection to the students.

According to USA OSHA's Blood-Borne Pathogen Standards (1996), recapping a needle is prohibited in order to reduce the risk of transmission of blood-borne pathogens ${ }^{11}$. Some of the studies done before stated that needles should not be recapped because of the risk of needle stick injury as the sharp point of the needle is brought towards the hand that holds the cap ${ }^{12}$. A study done by Naing et al. (1999) showed that $67.4 \%$ of the students recapped needles after use ${ }^{10)}$. The students might have been doing this because they were not aware of the correct practice and they just followed other health workers doing the same thing. A study done by Azmi (1997) revealed that $60.7 \%$ of the Accident and Emergency Department staff in Kuala Lumpur Hospital recapped needles after use and this showed that even health care workers who have more experience than students also carried out wrong practice ${ }^{13)}$. This study also showed that there was underreporting of accidents where in only $35.6 \%$ of cases accidents were reported.
This percentage was even lower than in the study done by Shen et al. (1999) where $43 \%$ of cases were reported to the management of the university ${ }^{2}$.

The findings of this study did not reveal any significant different in the level of knowledge of blood-borne pathogens and Universal Precautions among cases and non-cases even though the scores for the knowledge of both for cases were lower than for non-cases. This might be because all the cases already had training via formal lectures and seminars on blood-borne disease and a very small number of cases had not acquired knowledge of Universal Precautions. The knowledge of Universal Precautions may not correlate with reduced risk of occupational exposure among medical students ${ }^{14)}$. The risk perception of blood diseases for cases was higher, which might be due to previous experience with needle stick injury that made them aware of the risk ${ }^{13)}$ but it was not significant statistically.

Universal Precautions are a set of precautions designed to prevent transmission of HIV, HBV and other bloodborne pathogens among health care workers when providing first aid or health care with the consideration that blood and certain body fluids of all patients are potentially infectious ${ }^{11,15}$. The students with needle stick injuries in this study had a lower mean score of practice of Universal Precautions than students who did not have needle stick injury, but the mean scores for the knowledge of blood-borne diseases and Universal Precautions for both were almost the same. This showed that students would not be protected from injury if they did not follow correct procedures according to the Universal Precautions even though their knowledge was good. Osborn et al. (1999) stated that instruction on Universal Precautions was not sufficient but the students must be proficient in the safe conduct of clinical procedures ${ }^{16)}$. The results of this study also showed that the level of practice of Universal Precautions was inversely related to the episodes of needle stick injury, which means that the episodes of injury can be reduced if the level of practice of Universal Precautions is improved.

The administrators of the medical schools and the students have to play their roles in reducing the risk of needle stick injury and blood-borne infections. Koenig and Chu (1995) suggested that it is imperative that medical school administrators implement programs for risk reduction ${ }^{6}$. One of their suggested programs was that Universal Precaution procedures must be introduced in the preclinical years and constantly reinforced during each clinical posting.

Some guidelines which were set out by NIOSH of the USA in order to reduce the risk of needle stick injury are to eliminate the use of needles if possible, otherwise to implement the use of devices with safety features through engineering control. The injury trends and risk factors for these injuries need to be looked into. Like other health 
care workers, students also need proper training in the safe use and disposal of needles and Universal Precaution guidelines prior to exposure to needle stick as during their induction course and in each clinical posting. Some work practices that expose students to the hazard of needle stick injury need to be modified to make them safer. Promotion of safety awareness in the work environment is important as well as encouragement to report of all needle stick injuries. Students should be informed of the existing reporting system so that they will be aware of the reporting procedure. The management should evaluate the effectiveness of prevention efforts and provide feedback on performance ${ }^{3}$. Provision of free Hepatitis B vaccination to all students prior to clinical postings should be considered by the universities or the sponsoring bodies to ensure that all of them are protected from Hepatitis B infection before exposure starts. As far as prevention is concerned, to treat medical students similarly to permanent staff of the universities would be a great help since they are exposed to similar types of hazards.

It is the students' responsibility to protect their own safety and health as well as those of their friends. NIOSH of the USA also provides for a few roles for the medical students, such as avoiding the use of needles where safe and effective alternatives are available and using devices with safety features provided by the universities. Avoid unsafe work practices such as recapping needles and plan for safe handling and disposal before beginning any procedure with needles. Used needles are to be disposed of promptly in appropriate sharp instrument disposal containers. Students should report all needle stick injuries promptly to ensure appropriate follow-up care. They are advised to participate in blood-borne pathogen training and follow recommended infection prevention practices, including hepatitis B vaccination ${ }^{3}$.

One limitation of this study was the recall bias whereby the students might not remember exactly the number of needle stick injuries they had had in the past one year.

\section{Conclusion}

In conclusion, this study revealed that medical students from UKM, UM and UPM were at high risk of needle stick injury through hollow-bore needles during their clinical training which puts them at higher risk of bloodborne infection because the incidence of cases and episodes was high. The main reason for this was poor practice of Universal Precautions. Therefore, concerted efforts by both managements of the universities and the students are needed to prevent the risk of needle stick injury as well as blood-borne infections in medical students.

Ackonwledgments: This work would not have been possible without the cooperation of the study participants and the management of the three universities, and also many thanks to lecturers, family and friends for all their help and support.

\section{References}

1) C Doig: Education of medical students and house staff to prevent hazardous occupational exposure. CMAJ 162, 344-345 (2000)

2) NIOSH. Preventing needle stick injuries in health care settings. U.S. Department of Health and Human Services. Cincinnati: DHHS (NIOSH) Publication. 1999.

3) C Shen, J Jagger and RD Pearson: Risk of needle stick and sharp object injuries among medical students. Am J Infect Control 27, 435-437 (1999)

4) OSHA. Safer needle devices: protecting health care workers 1997. (online). http://www.thebody.org/osha/ saferneedle02.html (20 January 2002).

5) Ministry of Health of Malaysia. Incidence rate of needle stick injuries among health care workers within the ministry of health. Quality Assurance Indicator. 1998.

6) S Koenig and J Chu: Medical student exposure to blood and infectious body fluids. Am J Infect Control 23, 40-43 (1995)

7) PM Tereskerz, RD Pearson and J Jagger: Occupational exposure to blood among medical students. NEJM 335, 1150-1153 (1996)

8) FS Resnic and MA Noerdlinger: Occupational exposure among Medical students and house staff at a New York City Medical Center. Arch Intern Med 155, 75-80 (1995)

9) NN Naing, A Zulkifli and I Kamaruzzaman: Needlestick injuries in medical students. Malaysian Journal of Medical Sciences 2, 59-61 (1995)

10) NN Naing, A Zulkifli and I Kamaruzzaman: Puncture injuries during undergraduate medical training. Journal of Islamic.Medical Association 31, 270-273 (1999)

11) O'Neil, J.T. The blood-borne pathogen standard : a pragmatic approach. New York: Van Nostrand Reinhold. 1996.

12) J Jagger, E Hunt and BA Brand-Elinaggar: Rates of needle stick injury caused by various devices in a university hospital. The New England Journal of Medicine 319, 284-288 (1988)

13) Azmi M.T. Komplians terhadap amalan pencegahan universal di kalangan kakitangan perubatan Jabatan Kemalangan dan Kecemasan, Hospital Kuala Lumpur. Fakulti Perubatan, UKM. 1997; 1- 80.

14) SA Kwee and L Ka'anehe: Occupational exposures and knowledge of universal precautions among medical students. Hawaii Medical Journal 58, 21-23 (1999)

15) CDC. Universal precautions for prevention of transmission of HIV and other blood-borne infections (online). 2001. http://www.cdc.gov/ncidod/HIP/blood/ universa.html. (20 November 2001).

16) EH Osborn, MA Papadakis and JL Gerberding: Occupational exposures to body fluids among medical students. A seven-year longitudinal study. Annals of Internal Medicine 130, 45-51 (1999) 